\title{
Fogo de Dissolução e Fogo de Combinação
}

\section{Introdução}

A química é uma ciência que estuda a estrutura e a transformação das substâncias. Etimologicamente, enquanto Thomson [1] a associa ao antigo nome do Egipto, «Chemia» ou Keme, a terra que os Hebreus designavam por terra de Cham, pai de todos aqueles que fabricavam os instrumentos de cobre e ferro, segundo a descrição bíblica do Génesis [2], Faber [3] associa-a ao vocábulo «chymeia», designação dada por Olympiodoro, no século $\mathrm{V}$ da nossa era, às artes psamúrgicas praticadas no antigo Egipto. Ainda etimologicamente, há quem a associe às palavras gregas $\mathrm{X} \varepsilon \omega$ e $\mathrm{X} v \mu \alpha$, referidas à fundição e trabalho dos metais [4], e, naturalmente, ao vocábulo árabe al-kimia referido às múltiplas práticas e teorias particularmente empenhadas na transformação dos metais vis em metais nobres, e na produção do Elixir de Longa Vida, qual medicina universal - a Pedra Filosofal, que ao homem daria o segredo da eterna juventude, que entre os árabes teve exímios cultores, com Geber, Rhazes e Avicena à cabeça [5].

Nos finais do século XVII, quando a prática química arrastada na corrente do empirismo racional mais se voltava para o estudo da natureza e das transformações das substâncias e menos se preocupava com a Pedra Filosofal, não raro os seus cultores a ela se votam como à «sabedoria» do fogo. Pyrosophia e Pyrotechnia, a química é a philosophia per ignem. Qual anatomia dos mixtos, ela é a Arte que ensina a separar as diversas substâncias que se acham nos mixtos [6], ou, no sentido mais clássico, o puro do impuro, ou, ainda, em sentido espagírico, o útil do inútil, que no fogo tem o meio mais eficaz para todas as operações que a seu fim conduzem. O fogo transforma todas as coisas, como diziam os antigos, «ignis mutat res»; o fogo permite aos corpos entrarem em reacção química, dissolverem-se, dilatarem-se, fundirem-se ou evaporarem-se.

Em Portugal, já no século XVIII, é ainda bem patente esta ideia da química como ciência do fogo, como bem o demonstram a Pharmacopea Ulissiponense (1716) de João Vigier e a Pharmacopea Tubalense (1735) de Manoel Rodrigues Coelho. Numa e noutra, a acção do fogo, nos seus diferentes graus, é doutrina básica em que todo o verdadeiro químico se deve demorar [7].

Não cabe ao homem qualquer honra ou glória na invenção do fogo. O fogo não é de modo algum, uma invenção sua. Incêndios de florestas e outras ocorrências ígneas devidas a diversos fenómenos naturais, incluindo vulcões e trovoadas, foram observados pelo ser humano muito antes de ter sido capaz de ocasionar e manusear ele próprio o fenómeno a que assistia, provavelmente com fascínio e medo. Porém, cabelhe indubitavelmente, a glória da descoberta de variados modos de produzir por si-mesmo fogo em tudo igual àquele com que a natureza, aqui e além, o confrontava. E cabe-lhe, sobretudo, o mérito de o manusear para fins diversos, mérito esse de que se pode orgulhar como de façanha que o distingue de todas as demais espécies animais que com ele co-habitam o planeta Terra [8].

Sem o fogo, o homem, no seu desenvolvimento, ter-se-ia visto impossibilitado de ir muito além dos restantes animais, não obstante as suas diferentes capacidades de desenvolvimento intelectual. Os gregos compreenderam bem a importância que para o Homem representou o saber utilizar-se dele, deixando-o bem expresso na célebre lenda de Prometeu, um dos titãs meio-deus, meio-homem, sobreviventes do reino de Crono, que ardilosamente, entrou no Olimpo e daí retirou uma chama sagrada, iniciando-os, de imediato, em todos os usos que dela poderiam fazer. Quando Zeus se deu conta do acontecido, era já demasiado tarde para travar o processo de civilização que aos homens acontecera mercê do divino dom que Prometeu lhes pusera nas mãos. Colérico, mandou prender Prometeu, com grossas cadeias, no Monte Cáucaso, e ordenou que aí, todos os dias, uma águia lhe viesse devorar as entranhas, todos os dias, também, renovadas. Mas viu-se de todo incapaz de travar o processo civilizacional humano de desenvolvimento para a perfeição divina, iniciado com a ciência do fogo que ao homem fora dada [9]. E essa ciência não parou mais de crescer. De homo faber, o ser humano tornara-se Homo sapiens.

Tornado «mestre do fogo», o Homo Sapiens afastou-se cada vez mais das restantes espécies de animais, em avanço tecnológico e científico dia a dia mais acelerado. O manuseamento do fogo serviu-lhe, primeiro, para tornar os alimentos mais digestíveis; depois, para preparar objectos de argila com uma solidez nunca até então conseguida, e para trabalhar convenientemente os mais diversos metais.

Senhor do fogo, o homem trabalhou o vidro, tendo preparado não só preciosas peças para a construção e adorno das casas que habita, como também os vasos em que procede ao estudo de tantas e tantas reacções químicas, e ainda, as lentes e espelhos com que veio a construir o telescópio do astrónomo, o microscópio do biólogo, o laser da moderna tecnologia, etc.; senhor do fogo, o homem encontrou, na água, no carvão

a Departamento de Química - Universidade, 3000 Coimbra - Portugal. 
e nos óleos e gases minerais, potentes formas de energia. Só o manuseamento do fogo tornou possível a revolução industrial dos séculos XVIII-XIX e com ela o quase indescritível progresso científico e tecnológico dos nossos dias em que o homem conhece e dispõe de meios que lhe permitem o acesso a quantidades de calor, estritamente relacionadas com processos ígneos, praticamente incalculáveis e de delicado controlo.

Todavia, capaz de produzir e manusear o fogo de há milénios a esta parte, já que, na pior das hipóteses, o vem fazendo desde os tempos do Australopithecus Prometheus ou, pelo menos, do Sinanthropus Pekinensis, nos longínquos tempos de há quase um milhão de anos [8], o homem ainda hoje se interroga sobre o que seja o fogo e esses outros fenómenos com ele estritamente relacionados, quais sejam, por exemplo, o calor e a chama.

De Empédocles, Platão e Aristóteles, na Antiga Grécia, à revolução científica dos tempos modernos, nos séculos XVIXVII, ao Fogo foi inquestionavelmente atribuída a categoria de um dos quatro elementos, de parceria com a Terra, o Ar e a Água, base do sistema cosmológico, fisiológico e químico tradicional, servindo, tomados como as raízes de todas as coisas, quer para explicar a composição da matéria, quer para interpretar os estados de saúde e doença (através dos humores), quer, ainda, para explicar todo o movimento, e, por ele, a própria vida.

A essência de qualquer destes quatro elementos confinava-se a uma substância material associada a duas das quatro qualidades primárias objecto do tacto, o calor, o frio, o húmido e o seco. No caso do fogo, essas qualidades seriam o seco e o quente.

A hipótese metafísica da unidade da matéria domina toda a filosofia alquimista da Idade Média. Debruçada fundamentalmente sobre as operações químicas do labor alquímico, afirma-se que toda a matéria, na sua unidade primordial, incriada e eterna, se diversificara, no tempo, em apenas dois princípios: o enxofre, elemento masculino e activo; e o mercúrio, o elemento feminino e passivo. Subjacente à filosofia destes dois princípios estava, todavia, a filosofia dos quatro elementos do sistema aristoteliano, e, muito particularmente, a afirmação do fogo como elemento essencial e substância de referência de tais princípios. De facto, o enxofre seria quente, combustível, visível no estado «terra» e subtil no estado «fogo»; o mercúrio seria frio, fusível, volátil, visível no estado «água» e subtil no estado «ar».

No século XVI, Paracelso faria Escola relegando a teoria dos quatro elementos aristotelianos para segundo plano, e buscando a explicação de tudo nos chamados «tria prima», o mercúrio, o enxofre e o sal. Contudo, também para Paracelso e seus discípulos o fogo seria a grande base da explicitação de tais princípios, cuja identificação se faria por simples combustão ou por destilação, operações químicas que no fogo têm o seu agente imprescindível. Dos três princípios, o enxofre seria a causa da combustibilidade, da estrutura e da substância das coisas.

E o mesmo se verificaria com a chamada teoria dos cinco corpos simples ou dos cinco princípios (os três princípios activos de Paracelso, mais dois outros princípios passivos, $a$ água ou phlegma e a terra ou caput mortuum), primeiramente formulada por Joseph Duschesne e genericamente adoptada, ao longo de todo o século XVII, pelos iatroquímicos, do Jardin du Roi [10]. Porém, mais do que nunca, a atenção dos filósofos da Natureza se voltou com interesse inusitado para a natureza do fogo e do ar, e se deixou arrastar, com naturalidade, para os problemas sobre a natureza da combustão e das forças que dão consistência aos compostos [11].

Nos alvores do desenvolvimento da Ciência Moderna, Bacon, Galileu, Boyle, Leibnitz, Descartes, Hooke, Newton e muitos outros homens da ciência se interrogaram com afinco e paixão sobre a natureza do fogo, do calor, da luz, da chama, desejosos de encontrarem uma resposta satisfatória. VanHelmont, Scheele, J. Black, Boerhaave, Macquer, Crawford, Lavoisier, Laplace, Davy, Carnot, Thomspson (Conde de Rumford), R. Mayer, J. Prescott, Joule, Helmotz, Clausius, Lord Kelvin, Gibbs e Boltzmann são apenas alguns dos químicos e físicos mais notáveis que com afã empreenderam a mesma tarefa, estabelecendo todo um conjunto de princípios que nos finais do século XIX permitiram o estabelecimento da termodinâmica como uma ciência exacta. Para esse estabelecimento deram precioso contributo científico muitos outros químicos e físicos a quem a fama, por muitas razões, não bafejou de igual modo. Apraz-nos considerar no número deles, em especial, dois nomes portugueses: João Jacinto de Magalhães (1722-1790) e Vicente Coelho de Seabra (1764-1804).

João Jacinto de Magalhães deixou-nos um notável Ensaio sobre o fogo elementar e sobre o calor dos corpos [12]; e Vicente de Seabra escreveu, em 1787, uma não menos notável Dissertaçâo sobre o calor, aparecida a público em 1788, na Imprensa da Universidade de Coimbra, numa primeira exposição de matéria de filosofia natural que depois resumiria no primeiro volume do seu compêndio Elementos de Chimica, publicado pela mesma imprensa da Universidade de Coimbra, nesse mesmo ano de 1788 [13].

\section{Luz e Calor, manifestaçōes sensíveis do Fogo}

Antes mesmo da filosofia de Aristóteles, na sequência da doutrina de Empédocles, consagrar o fogo como um dos quatro elementos primordiais constitutivos da matéria, como princípio de leveza que quando se adiciona aos outros elementos diminui o seu peso, o fogo foi adorado como um ser animado e um deus benfazejo, fonte do primeiro movimento, sem o qual nada de visível ou vivo poderia existir.

Nesta sua sacralização, se encontra a primeira nota do carácter polémico que tem caracterizado a afirmação da natureza do fogo. Theophrastos, num pequeno tratado sobre o Fogo, admitindo, embora, o seu carácter primordial, afirma que ele difere, na sua simplicidade, dos outros três elementos, já pelas múltiplas aparências em que se manifesta (uma das quais é o calor), já pelas variadas formas em que se pode apresentar e pelo grande poder com que penetra em todas as coisas e se espalha por lugares sem conta [14]. Por sua vez, Olympiodoro, referindo-se formalmente às concepções das primeiras Escolas gregas, considerou-o o elemento activo de todas as coisas, o primeiro dos quatro elementos, elo de ligação dos três outros elementos primordiais, a Terra, o Ar e a Água [15]; nele estaria a causa da fluidez dos corpos, em 
geral, e da água e do ar, em particular, como, já nos tempos modernos, o salientaria Boerhaave [16]. Da maior ou menor quantidade da matéria do fogo que impregna os corpos, dependeria tão somente o estado físico em que existem, sólido, líquido e gasoso [17]. Sem o fogo não existiriam nunca nem a atmosfera, nem a hidrosfera; na sua total ausência, todo o corpo material seria porção de uma única realidade, a litosfera, num estado de entropia mínima, o mesmo é dizer, ordenação máxima. Actuante sobre os corpos, o fogo é fonte de desordem donde jorra, qual torrente de energia desordenada, o calor, seu atributo intrínseco que na chama e na luz que dela se irradia tem sua manifestação mais visível, primária e fulgurante.

Daí que não satisfeita com a simples afirmação do carácter elementar e primordial do fogo, a ciência moderna, na tentativa de melhor compreender, precisar e definir a sua natureza, o tenha feito debruçando-se precisamente sobre o estudo da natureza da luz e do calor em si-mesmos, num reportar-se de efeito a causa, em estrita coerência com o método de investigação que professava como primordial. Foi pois, na definição da natureza da luz e da natureza do eator que a ciência moderna buscou a compreensão da natureza do próprio fogo [18].

Nos dois casos, dividiram-se os homens de ciência entre duas concepções de cariz diferente.

Relativamente à natureza da luz, deparamos nos alvores do século XVII com uma teoria de carácter corpuscular e uma teoria de carácter vibracional. Descartes (1596-1650) e Newton (1642-1727) são, porventura, os principais paladinos da primeira; Fermat (1601-1655), Huygens (1629-1695) e Hooke (1635-1703), os grandes paladinos da segunda. Antes deles, encontramos em Kepler (1571-1630), Galileu (1564-1642) e Gassendi (1592-1655), em particular, algumas considerações vagas sobre a luz, referindo, nomeadamente, tratar-se de um movimento de um meio determinado, qual derrame contínuo de matéria de um corpo, ou projecção de corpúsculos, com uma velocidade de propagação praticamente infinita. Descartes ao explicar as cores, na sua obra Meteoros e, depois, na sua outra obra Dióptrica [19], dá-nos uma explicaçâo cinética pormenorizada do fenómeno luminoso. A luz seria constituída por pequenas esferas sem elasticidade, propagando-se no espaço com uma velocidade finita, animadas simultaneamente de um movimento rectilíneo de translacção (igual para todas as cores) e um movimento de rotação (diverso para as partículas responsáveis pelas diferentes cores). A sua propagação dever-se-ia a uma pressão transmitida instantaneamente através das partículas não-elásticas do meio transmissor, nomeadamente o fluido subtil que constitui o éter, do movimento das pequenas esferas que constituem o fluxo luminoso.

Newton, não obstante toda a cerrada crítica que teceu ao sistema cartesiano, adoptou a mesma teoria, servindo-se da analogia entre a propagação da luz e a emissão de pequeníssimos e muito rápidos projécteis, num meio sem qualquer atrito [20].

Fermat rejeitou a concepção corpuscular proposta por Descartes, defendendo que a luz consistia, antes, num movimento da matéria que se encontra entre o observador e o corpo luminoso, propagando-se de modo semelhante ao som, embora com uma trepidação muito mais rápida, tendo o éter como meio de propagação. Esta concepção de Fermat foi retomada por Huygens e por Hooke que a desenvolveram com mais pormenor, descrevendo a luz como «um movimento rápido de vibrações de amplitude muito pequena» que se propaga instantaneamente por impulsos simples, constantes e perpendiculares à linha de propagação [21].

Estas duas concepções, a corpuscular e a ondulatória, extremaram-se e como que assumiram aspectos irredutíveis com Newton e Huygens, cada um deles com convictos sequazes. Numa afirmação muito genérica, simplista e resumida, poderíamos, talvez, dizer que os físicos do século XVIII, com Daniel Bernoulli (1700-1782) e Euler (1707-1773), foram particularmente sensíveis à concepção corpuscular, enquanto que os físicos do século XIX, com Fresnel (1788-1827) e Maxwell (1831-1879), em particular, se mostraram mais sensíveis à concepção ondulatória. Os físicos do século XX, com Einstein (1879-1955) e De Broglie (1892-1987), tentaram a conciliação das duas, desenvolvendo a teoria corpuscular-ondulatória da radiação electromagnética, hoje, generalizadamente aceite e defendida.

A oposição e paulatina aproximação entre as concepções corpuscular e ondulatória sobre a natureza da luz arrastou consigo e marcou a diferença de posições sobre a natureza do calor, dada a íntima relação entre luz e calor, como fenómenos naturais. Uma vez mais, em resumo simplista, poderíamos dizer que a oposição entre aquelas duas concepções se reflecte em idêntica oposição entre uma concepção do calor como substância material, ainda que imponderável, consubstanciada na chamada teoria do calórico, e uma concepção do calor como movimento dos elementos constitutivos da matéria, a chamada teoria do movimento molecular.

Poder-se-ia dizer que qualquer destas duas teorias sobre a natureza do fogo remonta à própria Antiguidade Grega, onde já Platão (427-347 A.C.) distinguiria entre o fogo «elemento que penetra a matéria» e o calor, «movimento das pequenas partes da matéria", numa relação clara de causa (=0 fogo) e efeito $(=0$ calor). Assumindo a mesma distinção, Aristóteles (384-322 A.C.) descrevera o calor como «uma substância oculta formada por partes em perpétuo movimento».

Para Roger Bacon (1214-1294), no século XIII, a causa do calor (em termos platónicos, o próprio fogo) encontrava-se no movimento interno dos corpos. Séculos mais tarde, Francisco Bacon (1561-1626), Descartes, Newton, Boyle (16271691), Jean Bernoulli (1767-1748), e os já mencionados Daniel Bernoulli e Euler, são apenas alguns dos mais destacados defensores, sem grandes diferenças de fundo, da tese do calor como movimento, com origem na «vibração das moléculas» (Boyle), na «agitação das pequenas partículas que compõem os corpos» (Descartes), ou na «vibração do éter» (Newton).

Posição diferente foi defendida por Galileu, Nollet (17001770), Leibniz (1646-1716), Stahl (1660-1734), Crawford (1748-1795), João Jacinto de Magalhães, Boerhaave (16681738), Gravessande (1688-1742), Lavoisier (1743-1794) e Laplace (1748-1827), entre outros, até finais do século XVIII, para quem o calor era uma substância material, distinto do fogo e da luz, imponderável, para uns, ponderável, para outros. Nollet justificava a sua oposição à concepção do calor como movimento dizendo que este tende, por sua própria natureza, a extinguir-se, enquanto o 
fogo, e com ele o calor, tende a propagar-se. Por sua vez, Cottereau DuClos (? -1715) afirmava que o «espírito ígneo", o fogo, jé a causa do movimento e não seu efeito [22].

\section{A Teoria do calórico na química de Lavoisier}

No primeiro grande paradigma químico, com um carácter sistemático e programaticamente universal que foi o sistema flogístico, Stahl defenderia que o carvão e os corpos combustíveis se transformavam, pela combustão, em calor e luz; $\mathrm{e}$, reciprocamente, o aquecimento dos produtos duma combustão levaria à fixação da luz e do calor, com regeneração dos respectivos metais.

Para os flogistas, a teoria do fogo e da luz aparece, assim, estritamente relacionada com a da calcinação e combustão. O fogo, constituinte de todos os corpos combustíveis e que deles se separaria quando sujeito a combustão, mais não seria que o próprio flogisto, uma substância inflamável, sui generis, matéria condensada da luz e causa imediata das cores dos corpos.

A teoria do flogisto mantinha, deste modo, viva a doutrina de Paracelso sobre a existência de um princípio específico, o «enxofre», constitutivo de todos os corpos inflamáveis que se dissiparia quando estes fossem queimados. Apenas, em vez de afirmar que esse princípio era o "enxofre», afirmava ser ele o "flogisto».

Estreitamente relacionada com a teoria da calcinação e combustão, a teoria do fogo e da luz defendida pelos flogistas adoptou com naturalidade o carácter de "princípio de leveza» que Aristóteles assinalara como característica intrínseca do próprio fogo, uma vez que ao libertar-se dos corpos os deixava mais pesados, e ao fixar-se neles os tornava mais leves. O flogisto seria como que o princípio vital dos metais: tal como acontece quando o princípio vital de um ser vivo se escapa, o deixa mais pesado, jazendo imóvel sobre a terra, assim acontece na calcinação dos metais. Calcinar mais não seria que mortificar.

Defender da posição dos flogistas, Scheele sustentaria ser o fogo uma combinação do ar fixo (ácido carbónico) com o flogisto. Quando nesta combỉnação o ar fixo fosse mais abundante que o flogisto, o fogo manifestar-se-ia como luz; e quando a quantidade de flogisto fosse demasiado grande, ter-se-ia o ar inflamável [23].

Também porque estreitamente relacionada com a natureza da calcinação e combustão, a teoria sobre a natureza do fogo e do calor foi doutrina de particular relevância no processo da revolução química levada a efeito por Lavoisier e sua escola. Empenhado numa luta sem tréguas contra o flogisto, uma vez explicada a calcinação e a combustão, como explicada também a síntese da água e a própria respiração animal, como reacções em que o interveniente principal, para além dos metais e dos corpos combustíveis em causa, era um dos elementos componentes do ar-o oxigénio - e não o calor, actuando este apenas como agente externo, Lavoisier substanciou o calor num fluido ígneo, matéria comum do fogo, da luz e do calor, a que deu o nome de calórico. Espalhado por toda a natureza, este fluido seria uma matéria imponderável que ao combinar-se com a matéria ponderável do oxigénio, do hidrogénio, do azoto ou de quaisquer outros possíveis compostos, permitiria a existência destes no estado aeriforme como seu estado natural. Na combinação do oxigénio natural com os metais e os corpos combustíveis, o calor que com ele se encontrava combinado perder-se-ia e o oxigénio deixaria de existir no seu estado aeriforme natural [24].

$\mathrm{E}$ assim como a água, nos processos químicos e físicos, poderia actuar como água de combinação (a água unida em proporções bem definidas aos sais neutros e aos ácidos) ou como água de dissoluçâo (a água como solvente em que toda a sua massa, em proporções indefinidas, se encontra em equilíbrio com os sais nela dissolvida), também o fogo deveria ser considerado como fogo de dissolução, o fogo livre ou elementar, o responsável pelo aumento da temperatura dos corpos, que se encontra indefinidamente espalhado por todos eles, e o fogo de combinaçāo, parte integrante de cada corpo, em cada um dos diversos estados físicos em que possa existir, em quantidades características de cada um deles, e diferentes de corpo para corpo. Aquele seria um calor absoluto; este, o calor que J. Black designaria por calor latente, conhecido também, por outros, por calor específico, e que estava já a ser objecto de variadas determinações [25].

Afirmando que o fogo é matéria imponderável que se escapa com a chama, o calor e a luz, Lavoisier estava consciente do carácter polémico da posição que assumia. Ele próprio se fez eco da controvérsia reinante entre os físicos sobre esta matéria, contrapondo a posição que adoptava para si, a defendida pelos físicos que consideravam o calor como um fluido material espalhado por toda a natureza, em que todos os corpos se encontravam mergulhados, com a posição defendida pelos físicos que afirmavam ser o calor o resultado de movimentos insensíveis das moléculas da matéria. Fazendo-se eco dessa contravérsia, Lavoisier fez questão de sublinhar que certos fenómenos relacionados com o calor se explicariam mais facilmente por recurso à hipótese do calórico, enquanto outros pareciam ser mais consentâneos com a hipótese cinética, enquanto outros, ainda, se explicariam com igual facilidade por uma ou por outra. E concluia: «seja como for, uma vez que nos não é possível formular senão estas duas hipóteses sobre a natureza do calor, devemos admitir os princípios que lhes são comuns».

$\mathrm{E}$, de imediato, formula o primeiro e mais fundamental desses princípios: o princípio da «conservação do calor livre, na simples mistura dos corpos» [26].

Quando na combinação de dois ou mais corpos, o composto resultante tiver menos matéria de fogo do que a existente no estado de não combinação, uma porção de fluido ígneo antes combinado com os corpos que sofreram combinação, torna-se fogo livre que se dissipa com elevação da temperatura. Reciprocamente, haverá resfriamento sempre que haja absorpção de matéria do fogo numa qualquer combinação, tal como acontece, por exemplo, durante a evaporação.

Os estados sólido, líquido ou gasoso em que os diversos corpos podem existir dependem, fundamentalmente, da maior ou menor quantidade de calor que os penetra e que com eles se acha combinada. As substâncias aeriformes contêm uma quantidade muito grande de fogo combinado; a sua volatilidade mais não é que a maior ou menor facilidade com que se dissolvem no fluido ígneo [27]. 
Em Portugal, as duas concepções fundamentais sobre a natureza da luz e do calor eram conhecidas muito antes mesmo da reforma do ensino universitário a que procedeu o Marquês de Pombal, em 1772. Todavia, mais que uma posição controversa que dividia os curiosos da Natureza de além fronteiras entre dois grupos distintos, tais concepções aparecem-nos numa forma eclética, com destaque para a posição de Descartes e Newton.

Na Recreação Filosófica do oratoriano Padre Teodoro de Almeida, publicada em 10 volumes, em Lisboa, entre os anos de 1758 e 1800 , está bem expressa essa posição eclética: «o fogo - diz Silvio, adepto da Filosofia Antiga - é no nosso sistema um elemento mui seco e summamente quente como o define Aristóteles, o noso Mestre» [28]; «no meu sistema - responde-lheTeodósio, adepto da Filosofia Moderna - o fogo consta de umas partículas de materia mui sutis, as quaes de sua natureza se movem com um movimento vibratorio e tremulo, porem mui rápido, veloz e mui forte». E logo acrescenta: «que a materia do fogo seja mui sutil, é coiza que não necesita de prova; por quanto se vê que o fogo não é nenhuma materia crasa, pois penetra corpos grosissimos» e «que as particulas de fogo se movem com um movimento tremulo, e veloz, vê-se claramente, pois nenhum corpo dá movimento a outro sem que ele se mova a si» [29]. Embora insistindo no movimento das subtis partículas de que consta o fogo, sobre o qual Silvio nada diz, Teodósio assume inteiramente o carácter material do fogo; se para Silvio este é um elemento, para Teodósio ele é constituído por partículas próprias, dotadas de «um movimento trémulo e veloz», sem que a este movimento se atribua a própria essência do fogo. E outro tanto se pode dizer relativamente à concepção da luz que Teodoro de Almeida apresenta como sendo «em si mesma corpo, como concordão todos os Modernos, ou sejão cartesianos ou newtonianos» [30].

Respondendo a uma pergunta do seu discípulo Eugénio sobre o assunto, Teodósio diz textualmente: «estimo a pergunta, porque veio a bom tempo. No sistema dos Newtonianos a luz é fogo mui puro, e só difere do que vulgarmente se chama fogo, em ter as partículas mui raras, e espalhadas; mas na sentensa dos Gassendianos à grande diferença, e é: que as partículas da luz, ou da matéria etérea, sim tem movimento, mas é só o movimento que lhe dão, de sorte, que, se as deixarem, elas por si só não se movem: por iso de noite, tanto que apagámos a véla, que nos alumiava, ficamos sem luz; porque como se extinguindo a chama, que era quem movia as partículas da materia etérea, que estava na caza, ninguem a move; e como a não movem, fica sem luzir, como vos expliquei em seu lugar; porém as partículas de fogo por si só movem, de sorte, que basta desembarasalas das outras para se moverem naturalmente por si mesmas, e luzirem" [31].

Como corpo que era em si mesma, a não mero acidente que só pudesse existir «encostada à matéria», a luz na sua reflexão à superfície dos corpos, comportar-se-ia como qualquer bola que fosse lançada sobre essa mesma superfície.

Assumindo o carácter material do fogo e da luz, Teodoro de Almeida não ignorava a controvérsia inerente a esse mesmo carácter, qual era a da sua ponderabilidade ou imponderabilidade. Desde a Antiguidade, o fogo foi considerado leve, i.é., sem peso, já porque as labaredas em que se manifesta buscam o seu centro subindo no ar, ao contrário dos corpos «pesados» cujo centro natural estaria no centro da Terra, já porque se não encontrava diferença de peso entre um mesmo corpo mais ou menos aquecido. Teodoro de Almeida, pela boca de Teodósio, pronuncia-se claramente a favor da ponderabilidade do fogo: «a chama sobe para sima, mas iso não é porque seja leve de si; sobe para sima, porque o ar, que é mais pezado que a chama, a faz subir para sima; assim como o madeiro metido na ágoa sobe para sima, porque a ágoa que é mais pezada que ele, o faz subir» [32]. E para provar o peso do fogo refere a calcinação do estanho, do chumbo, do enxofre e do cobre, então considerada como simples incorporação de uma certa quantidade de fogo no seio de tais metais: «o estanho calcinado para formar o que chamamos vidro, com que os azulejos e vazos de barro ficão vidrados, depois da calcinação fica mais pesado do que antes de se meter no fogo, não obstante toda a materia que se evapora». E isto quer a calcinação fosse operada directamente por uma chama intensa que no processo de aquecimento poderia arrastar para dentro do corpo sob calcinação algumas partículas estranhas à própria chama, quer ela se realizasse por recurso a espelhos concavos para concentrar sobre o corpo a calcinar os raios solares, onde não haveria qualquer possibilidade de se introduzir no corpo senão partículas do fogow [33].

Com o novo ensino das matérias de Filosofia Natural introduzido na Universidade de Coimbra pela Reforma de 1772 , que as questões sobre a natureza do fogo, da luz e do calor enquadram-se mais perfeitamente na problemática suscitada pelos estudiosos de além fronteiras, com o confessado desejo, por parte dos estudiosos portugueses, de não só se manterem bem informados sobre todos os pormenores dessa mesma problemática, como também contribuirem positivamente para a sua elucidação. Prova-o a já citada Dissertação sobre o Calor de Vicente Seabra, onde o autor, «depois de expor todas as opinioens dos chimicos», manifesta «huma nova theoria fundada sobre raciocinios convincentissimos, e experiencias».

Seguindo de perto as teses da escola de Lavoisier, Vicente de Seabra, com originalidade própria, defende que o fogo «he hum fluido», «causa da fluidez, vivificação, e movimento dos corpos» que se pode apresentar num estado livre, a luz, fogo elementar ou calor absoluto, ou combinado com os corpos, sujeito à acção geral da lei da atracção ou afinidade química, já numa proporção específica e permanente para cada corpo (o calor específico), inteiramente insensível, já em porções super-abundantes, não-permanentes, sensíveis ao tacto e outros instrumentos de detecção (o calor mixto). Nas reacções químicas, das quais a combustão e a respiração animal são casos elucidativos, todas as trocas de calor ocorrem a nível do calor combinado, verificando-se sempre que «a quantidade de calor permanece sempre a mesma na simples mixtura dos corpos» [34].

\section{Referências}

[1] T. Thomson, The History of Chemistry (Arno Press, Nova lorque, 1975), pg. 9.

[2] Gen. IV, 22

[3] E. Faber, The Evolution of Chemistry (Ronald Press, Nova Iorque, 1969). pg. 15 ,

[4] R. Jagnaux, Histoire de la Chimie (Ed. Baudry et C.ie, Tom. I, Paris, 1891), pg. 4 . 
[5] J. Ruska. Methods of Research in the History of Chemistry in Ambix, vol. 1 (1937), pg. 21; A. R. Butler and R. A. Reid, Whence came Chemistry in Chemistry in Britain, April 1966, pp. 311-312.

[6] N. Lémery, Cours de Chimie, Paris, 1675.

[7] João Vigier, Pharmacopea Ulyssiponense, Galenica e Chimica (Pascoal da Sylva, Lisboa, 1716), pp. 299-334; Manoel Rodrigues Coelho, Pharmacopea Tubalense Chemico-Galenica (Officina de Antonio de Sousa Sylva, Lisboa Occidental, 1735), pp. 886-898.

[8] L. C. Eiseley, Man, The Fire-maker in Scientific American, vol. 91 (1954), pp. 51-68.

[9] L. Green, Stories of Ancient Greece (Paul Hamlyn, Londres, 1967), pp. 10-16.

[10] R. Hooykaas, Janus, vol. 41 (1937), pp. 26-28; A. G. Debus, Chemical Philosophy (Science History Publications, N. York, 1977), pg. 79.

[11] H. Metzer, Les Doutrines Chimiques en France du Début du XVII.e à la fin du XVIII.e siécle, Tom. I (Presses Universitaires de France, Paris, 1923), pp. 339-420.

[12] J. H. Magellan, Essai sur la nouvelle Théorie du Feu élémentaire et de la Chaleur des Corps (Imp. W. Richardson, Londres, 1780).

[13] Vicente Coelho da Silva e Seabra, Dissertação sobre Calor (Imprensa Real da Universidade, Coimbra, 1788).

[14] T. Robinson, Theophrastos on Fire in Chymia, vol. 5 (1959), pp. 51-63. [15] Manuscrito de S. Marcos, fls. 166 vs. ss, cit. in M. Berthelot, Les Origines de L'Alchimie (Ed. Georges Steinheil, Paris, 1885), pg. 25.

[16] R. Love, Some Sources of Herman Boerhaave's Concept of Fire in Ambix, vol. 19 (1972), pp. 157-174.

[17] M. Berthelot, La Révolution Chimique-Lavoisier (Ed. Félix Alcan, Paris, $1890)$, pp. $82,93,96$.

[18] P. F. Schurmann, Luz y Calor-25 Siglos de Hipótesis Acerca de su Naturaleza (Espasa-Escalpe Argentina, Buenos Aires, 1946); A. G. Debus, Fire Analysis and the Elements in the XVI.th and XVIII.th Centuries in Annals of Science, vol. 23 (1967), pp. 127-147; A. Donovan, James Hutton, Joseph Black and the Chemical Theory of Heat in Ambix, vol. 25 (1978), pp. 176190; G. Bachelard, Étude sur L'Evolution d' un Problème de Physique (Lib. Philosophique J. Vrin, Paris, 1927); J. R. Partington, A History of Chemistry, vol. IV (McMillan Press, Londres, 1972); M. Watanabe, The Caloric Theory of S. L. Metoalfe in British Journal for History of Science, vol. 17 (1984), pp. 211-213.

[19] R. Descartes, Dióptrica; Meteoros, Amsterdam, 1644.

[20] I. Newton, Optica, sive de reflexionibus, refractationibus, inflexionibus et coloribus lucis, Londres, 1704.

[21] R. Hooke, Micrographia, Londres, 1165, pg. 55.

[22] S. Cottereau DuClos, Dissertation sur les Principes des Mixtes Naturels Amsterdam, 1680), pg. 27.

[23] M. Bertholet, O. Cit., pp. 87; 97.

[24] R. Fox, The Caloric Theory of Gases from Lavoisier to Regnault, Oxford, 1971; A. L. Lavoisier et Laplace, Mémoire sur la Chaleur in Mémoires de l'Académie des Sciences de Paris, 1780, pp. 355 ss; (Oeuvres de Lavoisier, Imp. Impériale, Tom. II, Paris, 1862), pp. 283-333; A. L. Lavoisier, Traité Elémentaire de Chimie, 1789 in Oeuvres de Lavoisier, Tom. I (Imp. Impériale, Paris, 1864).

[25] A. Crawford, Experiments and Observations on Animal Heat and the inflamation of combustible bodies..., Londres, 1779; J. Black, Lectures on the Elements of Chemistry, Ed. J. Robinson; W. Ramsay, Life and Letters of J. Black, Londres, 1926; J. H. Magellan, O. Cit., pp. 167; 169-170; 172-173; Vicente Coelho da Silva Seabra, O. Cit., pp. 18-21; Idem, Elementos de Chimica, Tom. I, Real Officina da Universidade de Coimbra, 1788, pp. 22-25. [26] A. L. Lavoisier e Laplace, O. Cit., pg. 287.

[27] A. L. Lavoisier, Sur la Combinaison de la Matière du feu avec les fluides évaporables et sur la formation des fluides élastiques aériformes in Oeuvres de Lavoisier, Tom. II, pg. 212.

[28] P. Teodoro de Almeida, Recreação Filosófica (Officina Miguel Rodrigues, Lisboa, 1751-1800), Tom. III, (1752), 12.

[29] Idem, Tom. III (1752), 13.

[30] Idem, Tom. II (1752), 8.

[31] Idem, Tom. IV (1757), 14.

[32] Idem, Tom. III (1752), 20.

[33] Idem, Tom. III (1752), 23-25.

[34] A. M. Amorim da Costa, Da Natureza do Fogo e do Calor na Obra de Vicente de Seabra (1764-1804) in Actas do Congresso História da Universidade, no VII Centenário da sua Fundação, Coimbra, 1990 (in press).

\section{Se \\ gosta de ler o Boletim SPQ gosta de participar no Boletim SPQ gosta de ter as suas contas em dia gosta de dormir tranquilo}

\section{Então PAGUE A QUOTA}

Junto envio o cheque $\mathrm{n}^{0}$ Banco

referente à(s) minha(s) quota(s) da SPQ do(s) ano(s) de 19 _ a 1990 *. de de1990

\section{Assinatura}

* Em caso de dúvida telefone SPQ (01) 7934637 